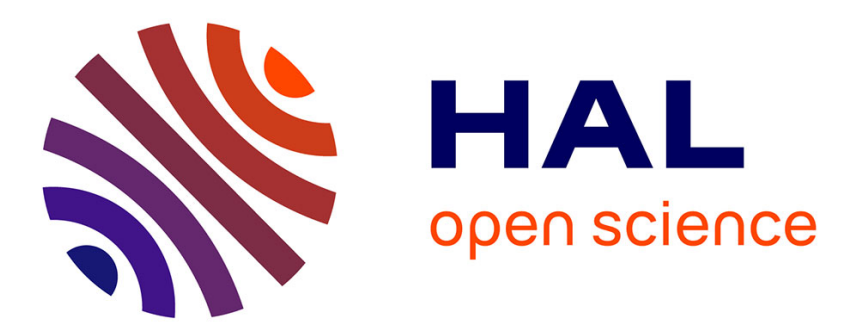

\title{
Implementation Strategies for Gender-Sensitive Public Health Practice: A European Workshop
}

Sabine Oertelt-Prigione, Lucie Dalibert, Petra Verdonk, Elisabeth Zemp

Stutz, Ineke Klinge

\section{- To cite this version:}

Sabine Oertelt-Prigione, Lucie Dalibert, Petra Verdonk, Elisabeth Zemp Stutz, Ineke Klinge. Implementation Strategies for Gender-Sensitive Public Health Practice: A European Workshop. Journal of Women's Health, 2017, 26 (11), pp.1255-1261. 10.1089/jwh.2017.6592 . halshs-01650202

\section{HAL Id: halshs-01650202 \\ https://shs.hal.science/halshs-01650202}

Submitted on 11 Feb 2020

HAL is a multi-disciplinary open access archive for the deposit and dissemination of scientific research documents, whether they are published or not. The documents may come from teaching and research institutions in France or abroad, or from public or private research centers.
L'archive ouverte pluridisciplinaire HAL, est destinée au dépôt et à la diffusion de documents scientifiques de niveau recherche, publiés ou non, émanant des établissements d'enseignement et de recherche français ou étrangers, des laboratoires publics ou privés. 


\title{
Implementation Strategies for Gender-Sensitive Public Health Practice: A European Workshop
}

\author{
Sabine Oertelt-Prigione, MD, MScPH, ${ }^{1,2}$ Lucie Dalibert, $\mathrm{PhD}^{3}$, Petra Verdonk, $\mathrm{PhD}^{4}$ \\ Elisabeth Zemp Stutz, MD, MPH, ${ }^{5,6}$ and Ineke Klinge, $\mathrm{PhD}^{3}$
}

\begin{abstract}
Objectives: Providing a robust scientific background for the focus on gender-sensitive public health and a systematic approach to its implementation.

Methods: Within the FP7-EUGenMed project (http://eugenmed.eu) a workshop on sex and gender in public health was convened on February 2-3, 2015. The experts participated in moderated discussion rounds to (1) assemble available knowledge and (2) identify structural influences on practice implementation. The findings were summarized and analyzed in iterative rounds to define overarching strategies and principles.

Results: The participants discussed the rationale for implementing gender-sensitive public health and identified priorities and key stakeholders to engage in the process. Communication strategies and specific promotion strategies with distinct stakeholders were defined. A comprehensive list of gender-sensitive practices was established using the recently published taxonomy of the Expert Recommendations for Implementing Change (ERIC) project as a blueprint.

Conclusions: A clearly defined implementation strategy should be mandated for all new projects in the field of gender-sensitive public health. Our tool can support researchers and practitioners with the analysis of current and past research as well as with the planning of new projects.
\end{abstract}

Keywords: gender, public health, implementation

\section{Introduction}

$\mathbf{S}_{\mathrm{s}}^{\mathrm{E}}$ X AND GENDER represent fundamental dimensions of human biology, psychology, and anthropology that influence self-perception, self-expression, and social interaction. Healthcare institutions and healthcare practice have neglected these determinants for many decades, with detrimental consequences for healthcare access and healthcare provision, for both women and men, resulting in health inequity and avoidable morbidity and mortality. ${ }^{1}$ Due to the 2015 landmark decisions by the $\mathrm{NIH}^{2}$ and the European Commis$\operatorname{sion}^{3}$ to mandate the inclusion of sex and gender-related factors into research funding applications, the consideration of sex and gender as research variables has experienced much attention. In the health sciences field both "sex," the biological components, as well as "gender," the sociocultural aspects that define identity are considered. ${ }^{4}$

While this is seen as a major leap forward toward the inclusion of sex-specific analysis into biomedical research it still does not ensure gender sensitivity in all areas of healthcare. Furthermore, while these important steps will significantly increase the ongoing knowledge production in the field, they will not guarantee that these results will find their way into practice. The inclusion of gender in public health analysis and practice has been advocated for decades ${ }^{5}$ and related information is more frequently available in public

\footnotetext{
${ }^{1}$ Institute of Legal Medicine, Charité-Universitätsmedizin Berlin, Berlin, Germany.

${ }^{2}$ Department of Primary Care, Radboud University Medical Center, Nijmegen, the Netherlands.

${ }^{3}$ Department of Health, Ethics and Society, Faculty of Health, Medicine and Life Sciences, Maastricht University, Maastricht, the Netherlands.

${ }^{4}$ Department of Medical Humanities, EMGO Institute for Health and Care Research, VU University Medical Center, Amsterdam, the Netherlands.

${ }^{5}$ Swiss Tropical and Public Health Institute, Basel, Switzerland.

${ }^{6}$ Institute for Social and Preventive Medicine, University of Basel, Basel, Switzerland.
} 
health than in other medical and healthcare-related disciplines. Although epidemiological data are supposed to be analyzed systematically by age and sex, ${ }^{6,7}$ this does not always occur in practice and, hence, much valuable information may be lost. Furthermore, this potentially gendersegregated analysis is rarely translated into gender-specific practice. Fundamental limitations in the transfer of research findings into healthcare practice have been identified in the last decade ${ }^{8}$ and the NIH in the United States enacted significant corrective efforts. ${ }^{9}$

Knowledge transfer or implementation research is rapidly developing its own methodologies, classifications, and practices. ${ }^{10-13}$ As the field of gender-sensitive interventions is growing, ${ }^{14}$ we aim at bypassing lag times between discoveries, trial, and practice and decided to focus on implementation strategy early in the process. While the focus of gender medicine has been primarily on (bio) medical aspects of healthcare, gender-sensitive public health addresses broader issues employing a systemic approach involving a wide array of stakeholders. These conditions imply the need for adequate design, targeted practices for implementation, and formal evaluation strategies.

The current work is the first attempt to assemble this knowledge in a systematic fashion. An expert workshop on sex and gender in public health was organized as part of the 2014-2015 European FP7-project "EUGenMed" (www .eugenmed.eu) dedicated to designing a roadmap for the implementation of sex and gender in biomedicine and health research. We report on this meeting, which aimed to (1) assemble available knowledge about methods and practices of incorporation of gender aspects into public health practice and (2) identify structural influences on practice implementation at all levels of the public health process.

\section{Materials and Methods}

A group of expert stakeholders $(n=23)$, representing a broad array of professional approaches and positions, were invited to a workshop taking place within the European FP7project "EUGenMed" (www.eugenmed.eu) in Brussels in February 2015. Specifically, we included practitioners, researchers, advocacy groups, politicians, policymakers, educators, international organizations, and funding bodies. We divided the participants into three heterogeneous groups and invited them to engage in moderated discussions in topicoriented round tables.

The discussion rounds were designed to match the three levels of evidence for public health interventions. ${ }^{15}$ Level one was entitled "priorities" and focused on urgency for action, motivation for action, and targets to lobby for action. Level two, "principles," identified the main messages for gender-sensitive action and assembled ideal conditions and structures for implementation. Level three, "practices," further detailed implementation in defining target groups, identifying communication nodes, and strategies for promotion and practical uptake. All participants rotated through the three tables. One moderator joined each table and conversations were audiorecorded and transcribed.

The three moderators summarized the discussion results. The workshop outputs were then analyzed in recursive rounds of synthesis to define emerging themes. The results were assembled in topic tables with focus on single steps of a structural implementation process. Furthermore, the identified strategies were compared with the recently published catalogue of implementation measures identified in the Expert recommendations for implementing change (ERIC) project. ${ }^{10,11}$ Since this project focused on taxonomy through extensive literature searches and expert consensus rounds, we decided to use the agreed-upon taxonomy as reference for our results. ${ }^{11}$ Proposed or employed strategies were aligned with the overarching strategies from the ERIC project to develop a general compendium of strategies for gender-sensitive prevention implementation.

\section{Results}

The following results are presented according to the flow of policy implementation, such as starting with framing an issue, identifying its urgency, and defining process steps for implementation. The latter process is split into substeps, such as identification of target groups and supporters, development of general communication strategies and of specific issue-based promotion strategies.

\section{Framing the issue: why do we need gender-sensitive public health practice?}

The participants identified several objectives to achieve through the application of a gender-sensitive perspective to public health practice (Table 1). Individual values and goals were thematically grouped into broader dimensions. The first and most frequently cited motivation for the inclusion of a gendered perspective into practice was for ideological and ethical reasons. Participants described gender sensitivity as a matter of social justice and health equity, as a fundamental human right, and as a measure against discrimination. Individual empowerment was also identified as a major potential achievement of gender-sensitive public health practice, in allowing for tailored choices and preventative offers. While most of the identified goals involved a proactive approach, the obligation to respect people's choices-even if

Table 1. Overarching Goals of Gender-Sensitive Public Health

\begin{tabular}{|c|c|}
\hline Dimensions & Values/goals \\
\hline Ideology & $\begin{array}{l}\text { (Health) Equity } \\
\text { Remove health inequalities } \\
\text { Social justice } \\
\text { Fight discrimination } \\
\text { Support fundamental rights }\end{array}$ \\
\hline Outcomes & $\begin{array}{l}\text { Health promotion for women and men } \\
\text { Better quality of life }\end{array}$ \\
\hline Practice & $\begin{array}{l}\text { Transdisciplinary teams working } \\
\text { on intersectional issues }\end{array}$ \\
\hline Empowerment & $\begin{array}{l}\text { Support informed choice } \\
\text { Offer tools for behavioral change } \\
\text { Acceptance of people's lifestyle choices }\end{array}$ \\
\hline Economy & $\begin{array}{l}\text { Achieve effectiveness } \\
\text { Reduce costs through improvement } \\
\text { of measures }\end{array}$ \\
\hline Policy & $\begin{array}{l}\text { Set actionable goals for health based } \\
\text { on differentiated analysis } \\
\text { Do not take status quo for granted }\end{array}$ \\
\hline
\end{tabular}


unhealthy - and the need to accept the status quo in some instances were also mentioned several times as part of a participatory and person-centered strategy. Last, the increase of efficiency and potential cost savings through a gendersensitive approach was mentioned. While potentially more costly during the set-up phase, attention to sex and gender could save significant follow-up cost stemming from, for example, pharmacological side effects, as well as insufficient adherence and uptake of prevention programs.

Overall, the participants described a holistic, multidimensional, and participation-oriented approach as the eventual goal for gender-sensitive public health.

\section{Most urgent needs: where should we focus our efforts?}

Clear strategies for implementation at different levels of the research and healthcare system as well as within the general society are the most urgent needs identified by the participants (Table 2). The need to increase awareness for the relevance of sex and gender for public health with a range of stakeholders, including the public, healthcare, and service providers, is still present. Furthermore, the fact that gendersensitive public health is neither women's health nor an issue of feminism in science, but a discipline that gains new insights and fosters innovation through the analysis of differences, still needs emphasizing. The potential gains for a gender-sensitive public health approach should be pointed out, and information about gender differences in risk inci-

Table 2. Most Urgent NeEds of Gender-Sensitive Public Health

\begin{tabular}{|c|c|}
\hline Strategies & Examples \\
\hline Raise awareness & $\begin{array}{l}\text { For sex and gender differences } \\
\text { (with the general public, with } \\
\text { health services providers, with } \\
\text { politicians/policymakers) } \\
\text { About gender-specific risk factors } \\
\text { Focus on health gains }\end{array}$ \\
\hline $\begin{array}{l}\text { Intervention targets } \\
\text { and priority issues }\end{array}$ & $\begin{array}{l}\text { Risk factors }(e . g ., \text { smoking }) \\
\text { Demographic change } \\
\quad(e . g ., \text { aging population, } \\
\text { migration, urbanization) } \\
\text { Chronic diseases and } \\
\text { metabolic diseases }\end{array}$ \\
\hline $\begin{array}{l}\text { Data production } \\
\text { and integration }\end{array}$ & $\begin{array}{l}\text { Produce more sex-segregated } \\
\text { and gender-sensitive data } \\
\text { Define a shared taxonomy } \\
\text { of classification } \\
\text { Define professional, economic, } \\
\text { and legislative resources needed }\end{array}$ \\
\hline $\begin{array}{l}\text { Develop translational/ } \\
\text { implementation } \\
\text { strategies }\end{array}$ & $\begin{array}{l}\text { How-strategies } \\
\text { What_evidence-based } \\
\text { public health } \\
\text { Where-cross-country, } \\
\text { context-specific work }\end{array}$ \\
\hline $\begin{array}{l}\text { Political lobbying/ } \\
\text { support }\end{array}$ & $\begin{array}{l}\text { Harness political will, } \\
\quad \text { find champions } \\
\text { Increase public funding } \\
\text { Promote regulation } \\
\quad \text { (potentially against } \\
\text { industrial interests) }\end{array}$ \\
\hline
\end{tabular}

dence and perception provided. Awareness raising needs to be combined with lobbying for increased political pressure to obtain specific funding and support gender-sensitive practice. Attention to sex and gender in data production and analysis as well as for the development of common taxonomies is also fundamental. Intersectional aspects need to be considered at this stage to allow for their incorporation into analysis once data are available. While all of these strategies concern implementation, workshop participants emphasized the need to define modes, practice standards, and specific strategies, so highlighting the relevance of methodological development.

\section{Process: what are the practical steps toward implementation?}

Identification of target groups. Workshop participants identified a vast array of potential stakeholders in the process of implementing gender-sensitive public health (Table 3 ). As well as the strictly professional community (e.g., public health practitioners, physicians, researchers, and pharmacists), we identified stakeholders from the civil society (e.g., schools and universities, NGOs, community initiatives, and unions) as particularly important to foster a participatory agenda. Many institutions or professional bodies have defined constituents, for example, professional societies represent physicians or researchers, politicians represent their electorate etc. This needs to be taken into account when promoting gender-sensitive approaches to these organizations.

Participants identified several examples of target groups with predefined access modes. The example of the World Health Organization (WHO) was discussed, where priorities are set by evidence, health impact, health burden, and inequalities. In such a framework, gender needs to be mainstreamed across all policy lines to achieve successful implementation. To gain access to

Table 3. Stakeholders for Gender-Sensitive Public Health

\begin{tabular}{ll}
\hline Stakeholders & \\
\hline Policymakers & NGOs \\
Politicians & Funding agencies \\
Governments & Researchers \\
Local governments & $\begin{array}{l}\text { Institutions for women's } \\
\text { and men's studies }\end{array}$ \\
Transnational regulators & Charities \\
$\quad(e . g .$, food, transport, & \\
built environment) & \\
$\begin{array}{l}\text { International Organizations } \\
(e . g ., \text { UN, ECDC, }\end{array}$ & Religious organizations \\
$\quad$ OECD, World Bank) & \\
Regulatory agencies & Trade unions \\
$\quad$ e.g., EMA, FDA) & \\
Physicians & General population \\
Nurses & Parents \\
Pharmacists & Relatives and families \\
& of patients \\
Health makers & Schools, kindergartens \\
Health insurers & Media (traditional and new) \\
Journal editors & Social media \\
Teachers in healthcare & Industry \\
Patients & \\
Patient organizations & \\
Professional societies & \\
\hline
\end{tabular}


Table 4. General Communication Strategies

\begin{tabular}{|c|c|}
\hline Sources & Examples \\
\hline Policy & $\begin{array}{l}\text { Champions are needed to bring the topic forward } \\
\text { Communication nodes (interested, active, communicative people) within organizations } \\
\text { should be made aware of the issue } \\
\text { Organize breakfasts or lunch sessions for policymakers who can support your message } \\
\text { Identify common goals with policymakers } \\
\text { Pool capacities, support multiplicators } \\
\text { Equip policymakers with information to convince others }\end{array}$ \\
\hline Traditional media & $\begin{array}{l}\text { Generate a knowledge/expert database for journalists } \\
\text { News portal for policymakers/politicians } \\
\text { Actively establish connection between traditional media and academia }\end{array}$ \\
\hline Digital media & $\begin{array}{l}\text { Develop specific websites as communication hubs for the community } \\
\text { Use YouTube videos for promotion of the issue } \\
\text { Develop appealing websites for relevant projects } \\
\text { Use social media both broadly to spread the message and selectively to support specific topics }\end{array}$ \\
\hline Science & $\begin{array}{l}\text { Contact and inform scientists on EU institution boards, professional alliances, and networks } \\
\text { Offer robust and concise information for NGOs and patient organizations } \\
\text { Identify a trending topic and present it with a gender perspective }\end{array}$ \\
\hline Location & $\begin{array}{l}\text { Identify locations in the community where people are receptive } \\
\text { (e.g., malls, pharmacies, initiatives) } \\
\text { Provide discussion forums in the community }\end{array}$ \\
\hline General considerations & $\begin{array}{l}\text { Give your project an attractive name and develop a recognizable logo } \\
\text { Include women and men both as targets and promotors of initiatives to emphasize } \\
\text { the mutual support and interconnection between sex-specific issues } \\
\text { Use infographics } \\
\text { Include "gender"' into the working group, institute's name if possible }\end{array}$ \\
\hline
\end{tabular}

such an organization, based on state and nonstate actors, representatives at the national level will have to be targeted to achieve inclusion of the topic. At the EU level, the process is similar, yet with a limited number of involved countries. Here, the influence of single countries or alliances of several countries can have a more direct impact on policymaking and could thus be addressed. All of these strategies call for direct connections between academia, the practice community, and politicians. Some groups might function as both a target group and a facilitator; for example, the general public can be a target population for receipt of information about the advantages of gendersensitive public health, but also a potent lobby that influences policy and organizations.

General communication strategies. The aims of gendersensitive public health and its potential advantages for the target populations/stakeholder groups need to be communicated more clearly, requiring the use of different modes and sources of communication (Table 4). While traditional media process information from their sources, digital media can serve as an unfiltered information supply and can be used by researchers and practitioners.

Scientists could identify trending topics in their area of expertise and add a gender-sensitive point of view to their analyses. Gender-sensitive analysis can be potentially applied to every human-centered research topic as it represents a uniquely crosscutting issue. When analyzing, for example, the uptake of a prevention program, risk factor distribution, or health literacy, incorporation of the gender dimension will most likely produce more nuanced results, which will improve the following implementation steps. Furthermore, they should ensure public engagement, and presentation of meaningful results and practices in lay terms, to broaden the target audience. Broadening of target audiences also fosters a more participatory approach, which guarantees increased usercenteredness in addition to continuous audience/participant feedback to the researchers about the project they are developing. Direct community contact can be achieved by targeting high-transit and target group-specific settings, for example, malls, pharmacies, or community centers. The choice of these contact areas will also harbor an intrinsic gender dimension, which should be taken into account. There should be a focus on identification of communication nodes within organizations, as these people are valuable assets in networking and rapid spreading of information.

The gendered nature of communication patterns and spread needs to be taken into account. In the case of policymakers and politicians, the main hurdle is often the set-up of an initial contact and the need to pitch short and concise information that the policymaker can further use with her or his audience.

Specific promotion strategies. The participants then identified specific strategies for the promotion and implementation of gender-sensitive public health with different target audiences such as research institutions, journals, and funding agencies (Table 5). All of these stakeholders will have to be addressed and informed about the need to include gender-sensitive practice. Ideally, mandatory trainings should be provided and guidelines developed for the inclusion of sex and gender into research and project design, reporting, and evaluation practices. Gender sensitivity in implementation should be considered early in project design. Several instruments are available in the area of policymaking. Gender impact assessment instruments, gender audits, and comparative effectiveness research for gender-sensitive policies should be used extensively. In addition, gender 
Table 5. Formal Promotion Strategies

\begin{tabular}{|c|c|}
\hline Targets & Examples \\
\hline Science/medicine & $\begin{array}{l}\text { Continuous incorporation of the gender dimension (into the literature, at conferences, in reports etc.) } \\
\text { Hold cross-sectoral transdisciplinary conferences with different stakeholders } \\
\text { Include gender dimension in proposals for nonspecific calls } \\
\text { Lobby journal editors, request formal guidelines for submission and review } \\
\text { Combine epidemiological data, behavioral information, and practice examples } \\
\text { to exemplify the impact of gender } \\
\text { Include gender into trainings for professionals } \\
\text { Include it into training, mentoring, and supervision-mandate if possible } \\
\text { Include it into national reports, even if not explicitly requested } \\
\text { Consider gender-sensitive implementation aspects during early planning of projects }\end{array}$ \\
\hline Policy/politics & $\begin{array}{l}\text { Establish a group of charismatic people to lobby politicians, funding agencies, and policymakers } \\
\text { Offer structured mentoring } \\
\text { Request a gender impact assessment for every policy } \\
\text { Request gender audits } \\
\text { Employ a selected group of experts to vet all documents, projects, publications } \\
\text { of the organization for inclusion of the gender dimension } \\
\text { Mainstream gender into agency's/organization's priorities } \\
\text { Request comparative effectiveness research (CER) for policy making } \\
\text { Take PR value into account when presenting the topic to politicians } \\
\text { Link gender to issues your target cares about }(e . g . \text {, costs, benchmarking, specific health topics etc.) } \\
\text { Work with the policy cycle, try to influence annual programs }\end{array}$ \\
\hline Community & $\begin{array}{l}\text { Use different types of social media to reach different audiences, tailor } \\
\text { audio-visual materials to the user } \\
\text { Use formal online health outlets to inform the public about the issue } \\
\text { Target specific communities with messages that are locally meaningful and they can relate to } \\
\text { Leverage corporate responsibility efforts to leverage a meaningful inclusion of gender aspects }\end{array}$ \\
\hline
\end{tabular}

mainstreaming at the institutional level needs to be scaled up, especially in large organizations. A combination of careful planning and adequate monitoring should allow for more effectiveness and more rapid adoption.

At the community level, tailored population targeting of gender-sensitive public health-related communications should be implemented. Gender-sensitive approaches could be promoted through existing health consultation offers, both online and offline, and connected to issues the public relates to.

\section{Structured process steps}

We summarized the inputs from the discussion sessions about ideal practice and implementation experiences and assembled them as compilation (Supplementary Table S1; Supplementary Data are available online at www.liebertpub .com/jwh) of possible practice approaches. Results were compared with the strategies from the ERIC project ${ }^{11}$ and gender-sensitive elements for implementation were specified wherever these could be identified. Fifty-eight items found a definite match and for an additional five relevance for gendersensitive practice appears very likely, but the audience identified no specific example. No definite match could be identified for only 9 of the 72 items.

Different stakeholders will apply different types of strategies based on their competences, needs, and settings; this has been incorporated into the table to facilitate the selection for specific endeavors.

\section{Discussion}

To our knowledge, the presented work is the first systematic assembly of gender-sensitive implementation strategies in public health. Following the implementation continuum, the workshop participants first defined the goals and needs for a gender-sensitive approach and then detailed the communication and implementation strategies needed for translation into practice. We provide a list of implementation practices that users at all levels of the healthcare system can draw upon for information and transfer.

Implementation practice and analysis requires a systemic approach that addresses both the practical steps within a project and the structural needs to translate the project idea into practice. ${ }^{16}$ Much of the work toward gender-sensitive practice has to be performed before the project starts and implies raising awareness, expertise, lobbying for political attention, for funding, and for adequate representation in the media. Hence, much of the discussion during our expert meeting focused on these activities identifying strategies, contacts, and steps to improve their outcome.

Challenges in the review processes, biased funding allocations, troubleshooting, and the publication process have all been addressed. Next to the intrinsic difficulties that these processes harbor for any researcher, the field of gender-sensitive research, practice, and training is complicated by the enmeshment of the issue and its political perception. Although specialists in the gender medicine and public health community point out that a gender-sensitive approach does not mean a focus on female careers or women's reproductive health, ${ }^{17}$ it is difficult for many audiences to separate the two and this still represents a hurdle in many ways. The reality that empowerment is indeed a part of gender-sensitive public health does not simplify this distinction. ${ }^{18}$ Gender-sensitive approaches frequently need to include female empowerment strategies to be effective; especially in regions of the world where healthcare access is not 
guaranteed to either women or men and in societies, organizations, or families with inequities in decision-making power. Addressing these issues goes beyond the spectrum of medicine and involves dimensions such as ethics, politics, economics, and education. ${ }^{19}$ Hence, the implementation of gender-sensitive approaches in public health requires more significant communication efforts than in many other domains.

Examples of gender-sensitive public health practice are quite limited, yet some very successful examples can be pointed out. The WISEWOMEN and Strong Women-Healthy Hearts project in the United States ${ }^{20,21}$ as well as the Prime Time Sister Circles ${ }^{22}$ both represent specific approaches to potentially high-risk women in the community. Both combine advantages of group dynamics with preventative counseling for traditional risk factors; in the case of the Prime Time Sister Circles empowerment and multiplication effects within the community are also addressed. A similar approach was chosen in the United Kingdom Football Fans in Training weight loss and healthy living program, which targets overweight/obese male football fans and uses gender-sensitized content and style, delivered in professional football clubs. ${ }^{23}$

Another successful project was a mass media intervention to prevent smoking among girls, which had a long-term effect on the behavior of the girls receiving the intervention compared with the ones obtaining standard prevention in school. ${ }^{24}$ These programs have all been extraordinarily successful; all have also required careful analysis, project development, and lengthy planning. The need for extensive knowledge of structural implementation hurdles is particularly evident.

The list that is being provided might not be universally appropriate, and it should not be perceived as a checklist. As the authors of the ERIC project point out in their publication $^{11}$ such a collection should be seen as a list of potential strategies that can be applied in specific cases-in sequence and in various combinations. No project should aim at including all 72 listed options, yet a multitude of them will apply at different times during project design, execution, and evaluation. Different stakeholders will most likely apply different strategies based on their needs and expertise, as we have tried to exemplify in our table.

The strategies presented here were suggested by a group of experts and do not represent the entire gender-sensitive public health community. Furthermore, although a representative of the WHO and one from Canada were part of the expert group, the main focus on the discussions was on experiences in a European context and, hence, might not be fully applicable to other regions. However, this risk should be minimized as attention was placed on formulating statements that could be intended as precisely, yet as broadly as possible.

This article represents the first systematic list of implementation strategies for gender-sensitive public health to aid knowledge transfer from science into practice. This collection can both aid the systematic analysis of completed projects to generate implementation and reproducibility blueprints and serve as inspiration during the development of new projects. Future implementation may profit from a wide distribution and application of the list by the practice community.

\section{Acknowledgments}

The current work was supported by EU grant EU/FP7 602050 (EuGenMed project).
The following experts have participated in the workshop and contributed substantially to the present article:

Olga Barna (Department of General Practice, Bogomolets National Medical University, Kiew, Ukraine), Marrie Bekker (Department of Clinical Psychology, Tilburg University, Tilbug, The Netherlands), Carole Clair (Faculty of Biology and Medicine, University of Lausanne, Lausanne, Switzerland), Lucie Dalibert (Department of Health, Ethics and Society, Maastricht University, the Netherlands), Miriam de Kleijn (general practitioner, Utrecht region), Isabel de la Mata (Principal Advisor for Health and Crisis Management, European Commission), Dirk Gansefort (Leibnitz Institute for Prevention Research and Epidemiology, Bremen, Germany), Olena Hankivsky (School of Public Policy, Simon Fraser University, Vancouver, Canada), Radu Iliescu (University of Medicine and Pharmacy "Gr. T. Popa." Iasi, Romania), Ineke Klinge (Department of Health, Ethics, and Society, Maastricht University, the Netherlands), Peggy Maguire (European Institute of Women's Health, Dublin, Ireland), Shanti Mendis (Chronic Disease Prevention and Management, World Health Organization, Geneva, Switzerland), Jörg Müller (Universitat Oberta de Catalunya, Barcelona, Spain), Sabine OerteltPrigione (Charité-Universitätsmedizin, Berlin, Germany and Department of Primary Care, Radboud University Medical Center, Nijmegen, the Netherlands), Dorota Sienkiewicz (The European Public Health Alliance, Brussels, Belgium), Astrid Stuckelberger (Institute of Global Health, University of Geneva, Geneva, Switzerland), Helen Sweeting (Institute of Health and Wellbeing, University of Glasgow, Glasgow, UK), Margo van den Berg (ZonMW, Program Diversity, Den Haag, the Netherlands), Petra Verdonk (Department of Medical Humanities, VU University Medical Center, Amsterdam, the Netherlands), Barbro Westerholm (Swedish Liberal People's Party, Sweden), Alan White (Center for Men's Health, Leeds Beckett University, Leeds, UK), and Elisabeth Zemp-Stutz (Swiss Tropical and Public Health Institute, Basel, Switzerland and University of Basel).

\section{Author Disclosure Statement}

No competing financial interests exist.

\section{References}

1. WorldBank. Gender Equality and Development. World Development Report. Washington, D.C: The World Bank, 2012.

2. Clayton JA, Collins FS. Policy: NIH to balance sex in cell and animal studies. Nature 2014;509:282-283.

3. Commission E. Promoting Gender Equality Research and Innovation, 2014. Available at: https://ec.europa.eu/programmes/ horizon2020/en/h2020-section/promoting-gender-equalityresearch-and-innovation Accessed December 30, 2015.

4. Krieger N. Genders, sexes, and health: What are the connections-and why does it matter? Int J Epidemiol 2003; 32:652-657.

5. Lawrence K, Rieder A. Methodologic and ethical ramifications of sex and gender differences in public health research. Gend Med 2007;4 Suppl B:S96-S105.

6. Aulakh AK, Anand SS. Sex and gender subgroup analyses of randomized trials. Womens Health Issues 2007;17:342-350.

7. Runnels V, Tudiver S, Doull M, Boscoe M. The challenges of including sex/gender analysis in systematic reviews: A qualitative survey. Syst Rev 2014;3:33. 
8. Peters DH, Adam T, Alonge O, Agyepong IA, Tran N. Implementation research: What it is and how to do it. BMJ 2013;347:f6753.

9. Westfall JM, Mold J, Fagnan L. Practice-based research"Blue Highways" on the NIH roadmap. JAMA 2007;297: 403-406.

10. Powell BJ, McMillen JC, Proctor EK, et al. A compilation of strategies for implementing clinical innovations in health and mental health. Med Care Res Rev 2012;69:123-157.

11. Powell BJ, Waltz TJ, Chinman MJ, et al. A refined compilation of implementation strategies: Results from the Expert Recommendations for Implementing Change (ERIC) project. Implement Sci 2015;10:21.

12. Proctor E, Silmere H, Raghavan R, et al. Outcomes for implementation research: Conceptual distinctions, measurement challenges, and research agenda. Adm Policy Ment Health 2011;38:65-76.

13. Proctor EK, Powell BJ, McMillen JC. Implementation strategies: Recommendations for specifying and reporting. Implement Sci 2013;8:139.

14. Alexander S, Walker EM. Gender-based health interventions in the United States: An overview of the coalition for healthier community initiative. Eval Program Plann 2015;51:1-3.

15. Brownson RC, Fielding JE, Maylahn CM. Evidence-based public health: A fundamental concept for public health practice. Annu Rev Public Health 2009;30:175-201.

16. Brownson RC, Colditz GA, Proctor EK. Dissemination and implementation research in health: Translating science to practice. Oxford: Oxford University Press, 2012.

17. Legato MJ. Beyond women's health the new discipline of gender-specific medicine. Med Clin North Am 2003;87: 917-937.

18. WHO: Women's empowerment and gender equality: Essential goals for saving women's lives. Geneva, World Health Organization, 2008.
19. Ostlin P, Eckermann E, Mishra US, Nkowane M, Wallstam E. Gender and health promotion: A multisectoral policy approach. Health Promot Int 2006;21 Suppl 1:25-35.

20. Folta SC, Seguin RA, Chui KK, et al. National dissemination of StrongWomen-Healthy Hearts: A community-based program to reduce risk of cardiovascular disease among midlife and older women. Am J Public Health 2015;105:2578-2585.

21. WISEWOMAN Workgroup. Cardiovascular disease prevention for women attending breast and cervical cancer screening programs: The WISEWOMAN projects. The WISEWOMAN Workgroup. Prev Med 1999;28:496-502.

22. Gaston MH, Porter GK, Thomas VG. Prime Time Sister Circles: Evaluating a gender-specific, culturally relevant health intervention to decrease major risk factors in mid-life AfricanAmerican women. J Natl Med Assoc 2007;99:428-438.

23. Hunt K, Wyke S, Gray CM, et al. A gender-sensitised weight loss and healthy living programme for overweight and obese men delivered by Scottish Premier League football clubs (FFIT): A pragmatic randomised controlled trial. Lancet 2014;383:1211-1221.

24. Worden JK, Flynn BS, Solomon LJ, Secker-Walker RH, Badger GJ, Carpenter JH. Using mass media to prevent cigarette smoking among adolescent girls. Health Educ Q 1996;23:453-468.

Address correspondence to: Sabine Oertelt-Prigione, $\mathrm{MD}, \mathrm{MScPH}$ Institute of Legal Medicine Charité-Universitätsmedizin Berlin Turmstraße 21, Haus N Berlin 10559

Germany

E-mail: sabine.oertelt-prigione@charite.de 